\title{
Solidaridad y conflicto entre combatientes del Grupo de Artillería 3 del Ejército Argentino en la guerra y posguerra de Malvinas
}

\section{Solidarity and conflict between fighters of the Group of Artillery 3 of the Argentine Army during Falklands war and postwar}

\author{
Germán Soprano \\ Instituto de Investigaciones en Humanidades y Ciencias Sociales \\ Universidad Nacional de La Plata \\ Consejo Nacional de Investigaciones Científicas y Técnicas \\ gsoprano69@gmail.com
}

(Argentina)

Recibido: 28-04-2019

Aceptado: 09-08-2019

Publicado: 05-06-2020

\section{Resumen}

El presente trabajo tiene por objeto el estudio de las formas de solidaridad y de conflicto en las relaciones formales e interpersonales entre el jefe, oficiales, suboficiales y soldados del Grupo de Artillería 3 del Ejército Argentino durante la Guerra y Posguerra de Malvinas. Las experiencias de combate en la guerra ponen a prueba la consistencia de esas relaciones en su dimensión formal o institucional e interpersonal. En la extrema realidad de la guerra, cuando los combatientes se exponían cotidianamente a la muerte, se suscitaban conflictos en las relaciones jerárquicas entre oficiales, suboficiales y soldados, al interior de cada uno de esos estamentos castrenses, y en los vínculos interpersonales entre todos los individuos. Pero en esos contextos también revelaban comportamientos altruistas, solidaridades y lealtades excepcionales. Esas 
solidaridades y conflictos producidos en la guerra, a su vez, se proyectaban-no sin modificaciones- durante la posguerra. Esas experiencias bélicas de solidaridad y conflicto serán analizadas en sus inscripciones y/o en sus relaciones con diferentes marcos temporales y escenarios espaciales tal como fueron vividos, reconocidos y conforme a los sentidos atribuidos por los propios veteranos.

Palabras Clave: Guerra de Malvinas, combatientes, solidaridad, conflicto.

\begin{abstract}
This work aims to the study of the forms of solidarity and conflict in interpersonal and formal relations between chief, officers, non-commissioned officers and soldiers of the Group of Artillery 3 of the Argentine Army during the Falklands War and in the postwar period. The experiences of combat in the war put to test the consistency of these relationships in its formal or institutional and interpersonal dimensions. In the extreme reality of the war, in which fighters were daily exposed to death, there were conflicts in hierarchical relationships between officers, non-commissioned officers and soldiers, inside each of those groups, and in the interpersonal relationships between all the individuals. However, in these contexts, they also revealed altruistic behaviors, solidarities and exceptional loyalties. Such solidarity and conflict produced in the war, in turn, projected -not without changes- during the postwar period. Those war experiences of solidarity and conflict will be analyzed in their inscriptions or in its relations with different timeframes as the veterans themselves lived, recognized and felt.
\end{abstract}

Keywords: Falklands War, fighters, solidarity, conflict.

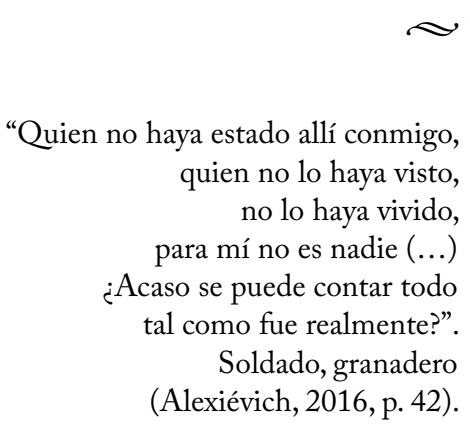

Introducción

El trabajo tiene por objeto el estudio de las formas de solidaridad y de conflicto en las relaciones institucionales e interpersonales entre el jefe, oficiales, suboficiales y soldados del Grupo de Artillería 3 durante la Guerra y Posguerra de Malvinas. El orden jerárquico, el ejercicio del mando, la obediencia y disciplina constituyen principios morales y dispositivos funcionales clave en la conformación de una organización militar y en su eficacia en el combate. Dichos principios y dispositivos son aprendidos e interiorizados por el personal de cuadros desde su formación básica en las escuelas de oficiales y suboficiales, y por los soldados conscriptos desde su incorporación a una unidad en cumplimiento del servicio militar obligatorio. Las experiencias de combate en la guerra ponen a prueba la consistencia de esas relaciones, tanto en su dimensión formal 
o institucional como en las tramas de vínculos interpersonales. En la extrema realidad de la guerra, cuando los combatientes se exponían cotidianamente a la muerte, se suscitaban conflictos en las relaciones jerárquicas entre oficiales, suboficiales y soldados, al interior de cada uno de esos estamentos castrenses, entre personal propio del Grupo de Artillería 3 y los "agregados", y en los vínculos interpersonales de todos los individuos. Pero en esos contextos se evidenciaban también comportamientos altruistas, solidaridades y lealtades excepcionales. Esas solidaridades y conflictos producidos en la guerra, a su vez, muchas veces se proyectaron -no sin modificaciones- en la posguerra.

El enfoque que he adoptado para comprender las perspectivas y experiencias de estos combatientes es una historia social y cultural o una antropología de la guerra, que para la Guerra de Malvinas cuenta en la Argentina con unas pocas pero sólidas e indispensables investigaciones de científicos sociales. ${ }^{1} \mathrm{~A}$ modo de hipótesis sostengo que las perspectivas y experiencias de los combatientes de la Guerra de Malvinas han sido configuradas en la guerra y la posguerra por las particulares trayectorias sociales y profesionales previas al conflicto, por las características de las unidades militares en las que prestaron servicios, por las situaciones vivenciadas por esas unidades en ciertos emplazamientos en el teatro de operaciones, por la pertenencia de su personal a una determinada Fuerza Armada, arma, especialidad, aptitud especial, por la jerarquía ocupada por ese personal en la cadena de mando, entre otros

1. Sobre este tema y sin ser exhaustivo: Guber (2004, 2008, 2016), Lorenz (2006, 2009, 2014), Corbacho (2003), Rodríguez (2009, 2015), Melara (2010), Pozzio (2015), Panizo (2016) y Chao (2017). factores. ${ }^{2}$ El enfoque adoptado conlleva el recurso metodológico a variaciones en las escalas de análisis espaciales y temporales, dado que la comprensión de las solidaridades y conflictos entre los veteranos requiere colocar como objeto de estudio relaciones y situaciones sociales vividas por los veteranos antes, durante y después de la guerra. ${ }^{3}$ Para demostrar mis argumentos utilizaré como fuentes el Diario de Guerra del Grupo de Artillería 3, entrevistas semi-estructuradas y en profundidad que hice a los veteranos propios y "agregados" de esta unidad -principalmente- entre diciembre de 2015 y mayo de 2016, trabajo de campo etnográfico que efectué en la ceremonia de "Bautismo de Fuego" en el cuartel del Grupo de Artillería 3 en Paso de los Libres (provincia de Corrientes) en abril de 2016, y de otros testimonios de dichos veteranos publicados desde la posguerra. ${ }^{4}$

2. Para un análisis de la formación y desarrollo profesional de los oficiales artilleros del Ejército Argentino: Soprano (2018a). Sobre el perfil y trayectoria profesional de Martín Antonio Balza, la adecuada instrucción y adiestramiento del personal del Grupo de Artillería 3 en los años 1980-1981 y el alistamiento de esta unidad antes de su despliegue en el teatro de operaciones: Soprano (2018b).

3. Soy consciente que esos relatos refieren a hechos ocurridos hace muchos años y, por ende, están sujetos a reelaboraciones. También -tal como reza el epígrafe que encabeza este texto- asumiendo que a los veteranos de todas las guerras les resulta difícil transmitir a un no combatiente- como el autor de este artículo- sus perspectivas y experiencias de guerra y que, además, quizá algunas quedarán transitoria o definitivamente confinadas en los estrictos límites de las memorias individuales y grupales de los combatientes.

4. Agradezco las observaciones efectuadas por dos evaluadores anónimos designados por la Revista. 


\section{El personal propio y "agregado" del Grupo de Artillería 3 en la Guerra de Malvinas}

El Grupo de Artillería 3 partió desde su cuartel el 9 de abril y arribó a las Islas Malvinas el 13 de abril de 1982. La unidad contaba con las Baterías de Tiro "A" y "B" con seis obuses Oto Melara de calibre $105 \mathrm{~mm}$ cada una y "agregó" la "Batería de Tiro "C" con otros 6 obuses similares procedentes del Colegio Militar de la Nación. El teniente coronel Martín Antonio Balza, además de jefe del Grupo de Artillería 3, era coordinador del Apoyo de Fuego de la Agrupación Ejército "Puerto Argentino" que tenía por misión la defensa perimétrica de esta localidad. Cumpliendo con esta última función coordinó el apoyo de fuego de su unidad con el Grupo de Artillería Aerotransportada 4 (con 17 obuses Oto Melara de calibre 105 $\mathrm{mm}$ ) y la Batería A del Batallón de Infantería de Marina 5 (con 6 obuses Oto Melara de calibre $105 \mathrm{~mm}$ ). Asimismo, Balza "agregó" a su unidad 2 cañones SOFMA de calibre $155 \mathrm{~mm}$ del Grupo de Artillería 101 -incorporados el 13 y 14 de mayo- y dos cañones SOFMA de calibre $155 \mathrm{~mm}$ del Grupo de Artillería 121 -uno arribado a Puerto Argentino el 13 de junio por la mañana y el otro ese día por la noche, no pudiendo este último ser trasladado a la zona de operaciones. Balza integró todos aquellos elementos en la Agrupación-Grupo de Artillería. ${ }^{5}$

5. Las fuerzas argentinas también tenían emplazadas en Puerto Argentino artillería antiaérea -que no dependía orgánicamente de Balza- conformada por el Grupo de Artillería de Defensa Aérea- GADA 601, una batería del Grupo de Defensa Aérea 101 agregada a la anterior unidad, el Batallón de Artillería Antiaérea de Infantería de Marina y el Grupo de Artillería Antiaérea de la Fuerza Aérea Argentina. En su conjunto integraban la Agrupación de Artillería de Defensa Aérea.
El personal propio del Grupo de Artillería 3 destinado a las Islas Malvinas estaba compuesto por 161 hombres: 13 oficiales (incluyendo al jefe), 39 suboficiales y 109 soldados conscriptos -105 incorporados con la clase 1962 y 4 con la clase 1963-. Antes de arribar a Puerto Argentino se sumaron a la unidad "agregados" de diferentes destinos: 17 oficiales y 24 suboficiales. Y en las islas se incorporaron otros "agregados": 3 oficiales, 5 suboficiales y 43 soldados conscriptos clase 1962. De modo que durante la Guerra de Malvinas, el Grupo de Artillería 3 llegó a contar entre propios y "agregados" con 35 oficiales (33 del cuerpo comando y 2 del cuerpo profesional), 69 suboficiales (56 del cuerpo comando y 13 del cuerpo profesional) y 152 soldados conscriptos, es decir, un total de 256 hombres. Al concluir la guerra el personal a órdenes de Balza -además de los heridos- solo tuvo dos bajas: el teniente Alberto Ramos y el cabo primero Miguel Ángel Quispe.

Quisiera llamar la atención sobre dos cuestiones derivadas de esta composición del Grupo de Artillería 3, que fueron decisivas en su desempeño en combate. Por un lado, la relación entre personal de cuadros y soldados propios y "agregados" era prácticamente de uno a uno; y, por otro lado, casi la totalidad de los soldados eran de la clase 1962, por ende, habían sido instruidos en el año 1981. A su vez, los motivos principales invocados por los protagonistas por los cuales no todo el personal se trasladó a las Islas Malvinas fueron al menos tres. Señalaban que se puso a disposición del Grupo de Artillería 3 una cantidad de aviones que era insuficiente para transportarlos a todos. Como consecuencia de lo anterior, gran parte del personal y material trasladado debía quedar en el continente. Y por último -y expresado más crudamente por algunos testimo- 
nios de oficiales, suboficiales y soldados- Balza decidió llevar sólo aquellos que consideraba en mejor aptitud para el combate. Dicha apreciación también fue refrendada por Balza de modo contundente cuando decía que, entre los oficiales y suboficiales que seleccionó para cruzar a las islas: "dejé en el continente a los que evidenciaban poca iniciativa o excesivo apego y reverencia hacia cánones preconcebidos, así como a los timoratos para tomar decisiones. Salvo alguna excepción, no creo haberme equivocado" (Balza, 2003, p.128).

\section{Solidaridades y conflictos en la guerra}

Por un lado, es dado reconocer circunstancias conflictivas en las relaciones con los oficiales, como ésta que me relató un soldado:

Un oficial se iba de la posición que teníamos en Sapper Hill y lo dejaba solo al soldado que estaba con él. En la guerra se ven las peores miserias (...) Balza lo mandó llamar [al oficial] y lo mandó al continente. Después supe que el tipo iba al pueblo a una casa a bañarse y -decían- hasta una mina [una amante] tenía. Yo jamás salí de mi posición. Cumplía órdenes. Balza nos cuidaba. Recorría las posiciones. Conversaba con vos. Preguntaba cómo estábamos, cuánto tiempo llevábamos de guardia. Hizo gestiones para que pudiéramos hablar por teléfono a casa. Dos veces pude hacerlo. Eso te cambiaba el ánimo. Igual que bañarte. ${ }^{6}$

Y, por otro lado, situaciones en las que se destacaban actitudes de oficiales que tenían buen ascendiente sobre soldados y suboficiales. Tal es el caso del jefe de Personal, el teniente Os-

6. Entrevista a Hugo Mango realizada por Germán Soprano, Paso de los Libres, 23 de febrero de 2016. car Martínez Conti. Como integrante de la plana mayor de Balza permanecía en el Puesto Comando, pero salía a recorrer las posiciones de las baterías en cumplimiento de una orden o bien a conocer personalmente el estado de sus miembros. Esa actitud tuvo su reconocimiento positivo. Para el soldado Hugo Mango:

Oscar fue un gaucho bárbaro en la guerra. Venía todos los días a conversar con nosotros a la batería a la hora en que se te cae el ánimo, a la tardecita. Algunos no entendían por qué hacía eso. Se enganchaba con nosotros, buscaba una relación más de afecto como superior. ${ }^{7}$

Pero que aquel joven teniente investido de una enorme responsabilidad como jefe de Personal cumpliera cabalmente con sus funciones y fuera un "gaucho bárbaro", esto es, un hombre dispuesto a ayudar a los otros, no lo dejó al margen de conflictos circunstanciales con sus subalternos. El cabo Cosme Hipólito Luna me relató que:

Cuando estaban bombardeando también salíamos a reparar los cables de teléfonos y en medio del campo no teníamos ningún pozo de zorro o refugio donde cubrirnos. Una vez un avión cortó los cables que nos comunicaban con Sapper Hill. Como nos estaban tirando, Balza no me dejaba salir, pero yo salí igual con un soldado. No sé cómo llegamos. Nos tirábamos al suelo cuando sentíamos que nos iba a caer un proyectil, nos levantábamos y seguíamos (...) Otra vez Balza nos dijo que habíamos hecho no sé qué cosa mal con el tendido y me mandó a arreglarlo. En ese momento no había fuego inglés. Como Martínez Conti era mi jefe tuvo que venir conmigo hasta Sapper Hill. No sé si Balza lo mandó, pero él sabía que como jefe era responsable de

7.Entrevista a Hugo Mango. 
las macanas que nos hubiéramos mandado. Estaba enojado. Oscar era un teniente joven y yo un cabo joven. En el camino íbamos callados como novios peleados. Él sacó un cigarrillo inglés y se puso a fumar. Yo le pedí si me daba uno y no me quiso convidar. Siempre compartíamos los cigarrillos, pero me lo negó. Yo también iba enojado así que le dije: ojalá se ahogue con ese cigarrillo [se sonríe al recordarlo] (...) Y así estábamos cuando nos agarra en medio del camino un cañoneo. Había dos piedras para guarecernos, yo agarré la más grande y a él le quedó la más chiquita. Nos pasaban las esquirlas por encima y nosotros nos apretábamos contra las piedras. Yo le gritaba: ¡cierre las piernas mi teniente! Por suerte, zafamos de esa (...) Después todo bien con Martínez Conti. Él pagó por nuestras macanas porque era el jefe. Por más que quisiera cumplir con todo, era el ayudante de Balza y no podía con todo ¡Cómo iba a hacer! Si Balza era muy exigente. ${ }^{8}$

En las exigencias diarias que imponía el combate y ante el cumplimiento de ciertas tareas, en muchos testimonios, los veteranos del Grupo de Artillería 3 me dijeron que "todos ponían el cuerpo", esto es, se comprometían en las mismas suspendiendo momentáneamente los roles formalmente asignados y jerarquías militares de cada integrante de la batería. Ello, obviamente, no suprimía estos últimos y las responsabilidades que imponían en la cadena de mando. Al respecto, un soldado de la Batería de Tiro "A" destacaba como positivo que oficiales, suboficiales y soldados sorteaban el orden de las guardias, para evitar que aquellos turnos más cansadores recayeran exclusivamente en los soldados o en los cuadros

8. Entrevista al suboficial principal Veterano de la Guerra de Malvinas (VGM) Retirado (R) Cosme Hipólito Luna realizada por Germán Soprano, Paso de los Libres, 23 de abril de 2016. de menor jerarquía. O bien que los oficiales de la batería en momentos críticos del combate "hacían de todo", esto es, incluso abrían y acarreaban cajones de munición, tareas que estaban asignadas a los soldados que hacían el servicio de la pieza. ${ }^{9} \mathrm{Y}$ un suboficial de la Batería de Tiro "C" me contó: "Éramos muy unidos en la batería. No había oficiales, suboficiales, soldados (...) Si bien al principio tuve algunos choques porque un sargento primero $y$ un [suboficial] principal no querían que fuera instructor porque yo era sargento. ¡ No querían que les enseñe!". ${ }^{10}$

El arrojo y la camaradería podían ir de la mano. Durante un bombardeo, el polvorín de la $\mathrm{Ba}$ tería de Tiro "A" fue alcanzado, se incendió e hizo explotar proyectiles y granadas que tenía almacenados. El teniente primero Caballero se detuvo ante el polvorín y constató:

solo quedaban cenizas, allí había quedado mi equipo individual de campaña y algunos efectos personales. En esos momentos se acerca un soldado y me dice: 'Mi teniente primero, lo único que pude salvar de su equipo fue una manta y esta bolsita conteniendo algunos elementos de aseo'. Seguidamente lo reprendí severamente por haber arriesgado su vida para rescatar mi equipo, no tenía sentido semejante acción, a lo que el soldado me respondió bajando la cabeza, compungido, por la reprimenda recibida: 'Sin su equipo, con este clima, pronto se moriría de frío'. No podía entender mi actitud, creía que había hecho lo que debía. Ante esa muestra de valentía, solidaridad y lealtad, le di un abrazo tratando de que comprendiera lo emocionado y agradecido

9. Entrevista a Hugo Mango.

10. Entrevista al suboficial mayor VGM (R) José María González Fernández realizada por Germán Soprano, Paso de los Libres, 22 de febrero de 2016. 
que estaba por su actitud (Caballero, 1999, p. 86).

De igual modo, el sargento José María González Fernández señalaba que cuando en los últimos días de combate recibieron de Balza la orden de adelantar piezas de la Batería de Tiro "C" -para anticipar el avance británico sobre Puerto Argentino y dar cobertura a las tropas argentinas que lo interceptaban o que iban replegándose-, oficiales, suboficiales y soldados debieron mover las piezas hasta una nueva posición cercana a la línea de combate. En esa posición, los disparos de contrabatería que recibían del enemigo eran tan intensos que:

Balza relevaba al personal por el tremendo cansancio y riesgo que se producía en esas posiciones. En los últimos días a [el teniente primero] Tessey lo relevó [el teniente primero] Navone. Tuvimos que mover dos piezas hasta Monte Longdon como unos dos mil metros. Por esa acción Navone y yo recibimos la condecoración al valor en combate. ${ }^{11}$

En otras ocasiones, el arrojo en el combate podía ser un atributo moral que costara manifestarse. Es que una cosa es declamarlo y otra muy diferente es hacerlo emerger en los hechos cuando el enemigo bombardea sistemáticamente las posiciones de las piezas de artillería propias. El teniente primero Caballero ordenó a los hombres de su batería que ocuparan nuevamente los puestos de combate, tras haber recibido fuego de contrabatería. Al hacerlo constató que un soldado no salía de su pozo. Cuando verificó que no estaba muerto ni herido le gritó que no fuera cobarde y retomara su puesto como telefonista:

11. Entrevista al suboficial mayor VGM (R) José María González Fernández.
En una pausa de fuego, se acerca y me dice que lo perdone, que no era por cobardía que no salía de su pozo, sino que él quería salir, pero sus músculos no respondían a las órdenes de su cerebro. Luego de pasados algunos minutos y viendo la intensidad del combate en que estábamos metidos, hizo un gran esfuerzo por sobreponerse y controlar el cuerpo. Así salió del pozo y controló su puesto. Se mantuvo a mi lado, hasta el final de los combates. Luego este soldado, cuando yo les ordenaba 'a los pozos' era el último en ocuparlos y el primero en salir del suyo cuando les pegaba el grito ocupar sus puestos'. La explicación es que había pasado por un momento de shock por el intenso fuego de contrabatería, un fenómeno nada raro en la conducta de los hombres en el combate. Lo importante es que él había logrado sobreponerse al miedo. Allí aprendí que eso se puede superar si el combatiente tiene buena formación moral y si en todos los niveles de comando se conduce con el ejemplo personal (Caballero, 1999, p. 87).

Sapper Hill fue una posición permanentemente castigada por el fuego británico. El soldado Horacio Ghittoni era allí observador adelantado del Grupo de Artillería 3 y, como tal, debía reglar los fuegos de las baterías propias. Pero las comunicaciones telefónicas se interrumpían cuando los proyectiles destrozaban el tendido de cables y las comunicaciones eléctricas eran localizadas por el enemigo y utilizadas para batir sobre las piezas de artillería y/o sobre quienes reglaban el fuego:

Los ingleses estaban batiendo mi posición. Navone [el oficial de la Batería de Tiro "B"] me decía que tenía que comunicarme por radio y yo le decía que si lo hacía [los británicos] me iban a matar, porque me ubicaban y me pegaban con sus bombazos. Navone llegó a decirme que era un hijo de puta, un 
cobarde, un traidor a la patria. Yo cuando hice la colimba había sido su asistente, teníamos una buena relación. Me tenía mucha confianza, cuando viajaba le cuidaba la casa (...) Balza después que Navone me dijera todo eso me fue a buscar y me dijo que tenía quejas sobre mí. Yo le expliqué qué había sucedido y me dijo que me quede [en esa posición en Sapper Hill]. ${ }^{12}$

Esa conflictiva situación entre este oficial y ese soldado, no obstante, conllevó muchos años después una reconciliación entre ambos. "Cuando Navone volvió después destinado a [Paso de los] Libres me mandó una carta con un soldado diciéndome que quería hablar conmigo. Fui a verlo y me dijo que teníamos que olvidar aquello. Nos abrazamos y lloramos". ${ }^{13}$ Supe también que una reconciliación similar se había producido entre un soldado y un suboficial que habían tenido conflictos en la guerra y que -muchos años después- en una ceremonia del "Bautismo de Fuego" del Grupo de Artillería 3 se estrecharon en un fuerte abrazo. ${ }^{14}$ Pero esos conflictos podían no ser superados en la posguerra. Esto fue lo que me señaló un soldado veterano en una conversación informal durante un evento de la ceremonia de conmemoración del "Bautismo de Fuego" en abril de 2016, después que ambos escucháramos las críticas que un suboficial veterano formulara en una conversación con otros contra algunos oficiales veteranos de la unidad por su desempeño en la guerra. Aquel soldado me dijo: "Yo no estoy de acuerdo con lo que dijo [el suboficial]. Hay algunas cosas que prefie-

12. Entrevista a José Horacio Ghittoni realizada por

Germán Soprano, Paso de los Libres, 22 de abril de 2016.

\section{Entrevista a José Horacio Ghittoni.}

14. Conversación informal con un oficial en actividad del Grupo de Artillería 3 y Germán Soprano, Paso de los Libres, febrero de 2016. ro olvidar. Después de la guerra todos somos hermanos. Hay cosas que pasaron y para mi quedaron allá". ${ }^{15}$

La producción de solidaridades y conflictos entre o intraestamentos militares o interpersonales en una guerra es casi una consecuencia normal de esas circunstancias en las que la posibilidad de vivir o morir está directamente relacionada no sólo con la capacidad del enemigo de infringir daños, sino con la capacidad de coadyuvar los recursos humanos y materiales propios contra la fuerza de aquel adversario. La confianza/desconfianza personal, corporativa, profesional o de otro tipo establecida entre los miembros de la unidad o subunidad era un atributo social que no sólo los estrechaba/ distanciaba en sus relaciones formal o informalmente definidas, sino también estaba en la raíz de la producción de solidaridades o de eventuales conflictos. De modo que, la cohesión del "espíritu de cuerpo" del personal de la unidad en situaciones de extrema conflictividad era factor decisivo en el cumplimiento de su eficacia en combate. Esa cohesión comenzaba a construirse en la instrucción y el adiestramiento del personal y en el alistamiento de la unidad en tiempos de paz. Tal fue el caso -entre otros- del cabo primero Omar Alberto Liborio y los soldados Clase 1962 de "su pieza" que habían hecho el servicio militar el año anterior en el Grupo de Artillería 101, fueron convocados y reincorporados a esa unidad al inicio de la guerra y "agregados" al Grupo de Artillería 3. Liborio me contó que los soldados de su pieza estaban bien cohesionados como grupo:

15. Conversación informal con un suboficial retirado y un soldado veterano del Grupo de Artillería 3 y Germán Soprano, Paso de los Libres, abril de 2016. 
Yo reuní a mis soldaditos, eran diez, y les dije que íbamos a cruzar. Les dije que si alguno de ellos no quería ir me lo hiciera saber, que elegía a otros. Les dije que si alguno no quería ir no se lo iba a echar en cara. Yo quería que fueran preparados para no volver. Todos eran clase 62. Todos. El año anterior los había tenido conmigo. Habíamos tenido [con la unidad] cuatro salidas al terreno, a Estancia Don Alejandro cerca de Junín. Habíamos hecho instrucción diurna y nocturna y tiramos con munición de guerra, así que fuimos muy preparados (...) Al día siguiente nos juntamos y tomó la palabra el soldado Gabriel Cepeda y dijo que si iba yo iban todos. Para mí fue una satisfacción muy grande (...) A los pocos días de estar en Malvinas, siete días, se me reventaron los oídos. Me salía sangre. A los ocho días me salía pus. Yo sabía que si me mandaban al hospital, la guerra se terminaba para mí. Así que me negué. Yo había llevado a mis soldados hasta ahí y mi compromiso con ellos había sido que íbamos para no volver. ${ }^{16}$

El modo en que el cabo primero Liborio planteó a sus soldados la decisión de acompañarlo con "su pieza" a las Islas Malvinas da cuenta -casi de un modo ideal- cómo opera el "espíritu de cuerpo" en una organización militar cuando sus miembros estrecharon sólidos lazos sociales en el curso de la instrucción y el adiestramiento. Esos lazos sociales suponen saberes y prácticas técnicos y valores morales compartidos que ligan las relaciones interpersonales de sus miembros. Como acertadamente señalan los autores del libro que relata la historia del Grupo de Artillería 101 en la Guerra de Malvinas, el "ascendiente" de oficiales y suboficiales sobre:

16. Entrevista al sargento VGM (R) Omar Alberto Liborio realizada por Germán Soprano, Ascensión, provincia de Buenos Aires, 29 de junio de 2016. sus hombres supone que el subordinado siga sus órdenes voluntariamente, sin que medie la jerarquía que ostenta sobre sus hombros. Esto no siempre se logra y constituye el desafío más importante que tiene que enfrentar quien ejerce el comando de una organización. Esto es más difícil en una unidad militar, ya que esa obediencia debe llevar a los subordinados a avanzar "hacia el lugar desde donde vienen las balas" y no al revés (Grupo de Artillería 10, 2012, pp. 34-35).

Asimismo, algunos de los conflictos entre el personal del Grupo de Artillería 3 durante la guerra adquirieron en la inmediata posguerra resonancia institucional dado que, cuando el 6 de agosto de 1982 Balza presentó al Ejército el Informe de Operaciones del Grupo de Artillería 3 con carácter de declaración jurada, consignó el negativo desempeño en la guerra de un oficial y tres suboficiales que servían en su unidad. El teniente primero Julio Manuel Santamaría, "agregado" de la Escuela de Inteligencia, fue sancionado en dos oportunidades, tras lo cual Balza lo relevó. El motivo por el cual obró de ese modo fue porque Santamaría se ausentó de su puesto de combate como observador adelantado:

sin autorización, sin aviso y sin causa justificada, con los agravantes de: ser reincidente en la comisión de dicha falta, y al ser observado por el J GA3 en el sentido de que una reiteración más motivaría su relevo, expresó: Estamos en guerra mi Tcnl. y si lo hace Ud no va a ascender. ${ }^{17}$

Balza dejó constancia también que lo reencontró en el campo de prisioneros de San Carlos y

17. Martín Antonio Balza, Informe de Operaciones del Grupo de Artillería 3. 6 de agosto de 1982. pp. 27-28. Archivo Personal del teniente general VGM (R) Martín Antonio Balza. 
que allí Santamaría fue "observado seriamente" por el capitán de navío Hassey de la Armada Argentina "a raíz de una contestación reñida con la ética militar". E hizo constar que envió a la Escuela de Inteligencia un Informe Especial de Calificación del Causante donde dejó asentado que el mencionado oficial "adoptó reiterados procedimientos reñidos no sólo con la ética profesional, sino también con el comportamiento de un oficial en combate. Fue un mal ejemplo para sus subalternos, y un elemento conflictivo en una situación trascendente para la Nación". ${ }^{18}$

Los casos de los suboficiales eran los siguientes. Como encargado de la Batería de Tiro "C" el sargento ayudante Jorge Alberto Maza -"agregado" procedente del Liceo Militar General Paz- tuvo un "comportamiento y rendimiento" que "no fue ejemplar", algo inadmisible en un encargado de subunidad. Durante las últimas horas de combate concurrió al Hospital de las Fuerzas Armadas "por una causa que no fue debidamente aclarada, permaneciendo en el citado hospital un tiempo que no pudo justificar" en el día - 13 de junio- en que se vivieron los combates más intensos. ${ }^{19}$ Por otro lado, el sargento ayudante Néstor Horacio Jara era encargado de la Batería de Tiro "B" y como tal hasta el 13 de junio tuvo un desempeño "altamente satisfactorio, siendo el mejor encargado de subunidad”. Sin embargo, ese día acompañó a un herido al Hospital "cuando no le correspondía esa misión" y permaneció allí "aproximadamente desde el mediodía hasta la noche", siendo por ello "relevado como encargado de subunidad por no gozar de mi confianza como

18. Martín Antonio Balza, Informe de Operaciones del Grupo de Artillería 3. 6 de agosto de 1982. pp. 27-28.

19. Martín Antonio Balza, Informe de Operaciones del Grupo de Artillería 3. 6 de agosto de 1982. p. 29.

60 consecuencia del proceder citado, y no haber sido ejemplo de sus subordinados". ${ }^{20}$ Por último, el sargento primero Luis Roberto Alonso De Armiño -"agregado" del Liceo Militar General Espejo- era jefe de pieza de la Batería de Tiro "C" que "durante el trascurso del combate tuvo momentos de vacilación" y "no fue ejemplo de sus subalternos, al extremo que en una oportunidad un soldado de su pieza le pidió `que se fuera, que él se haría cargo”. ${ }^{21} \mathrm{En}$ relación con la inclusión de esta situación conflictiva en el Informe de Operaciones del Grupo de Artillería 3 confeccionado por Balza a su regreso al continente, un oficial veterano de la unidad me dijo:

Esto también fue un sesgo importante del ejercicio del mando de Balza. Esto [el comportamiento de este oficial y suboficiales] pudo haberse ocultado en el presupuesto que podría afectar al 'prestigio' de la unidad y sin embargo no fue así", pues se informó al Ejército de lo sucedido.22

Por contraste con estos comportamientos, Balza destacó en ese Informe los "actos de valor" de los oficiales, suboficiales y soldados que actuaron "bajo el fuego de la artillería y la fuerza aérea enemiga, constituyéndose en un ejemplo digno de imitar, que arrastró a superiores, subalternos y camaradas, y coadyuvó a sobreponerse y superar condiciones de combate notoriamente adversas". 23

20.Martín Antonio Balza, Informe de Operaciones del Grupo de Artillería 3.6 de agosto de 1982. pp. 29-30.

21.Martín Antonio Balza, Informe de Operaciones del Grupo de Artillería 3. 6 de agosto de 1982.p. 30.

22. Comentario informal de un oficial VGM del Grupo de Artillería 3 al autor. No consigno el nombre del oficial pues no tengo certeza de estar autorizado para hacerlo.

23. Martín Antonio Balza, Informe de Operaciones del Grupo de Artillería 3.6 de agosto de 1982. p. 30. 


\section{Perspectivas y experiencias de la guerra en la posguerra: la ceremonia del "Bautismo de Fuego"}

Que los conflictos al interior del Grupo de Artillería 3 en la Guerra de Malvinas tuvieran un alcance circunscripto o limitado no sólo es un hecho que puede constatarse sirviéndonos de la documentación oficial y de los testimonios de sus protagonistas, sino en virtud de que es una unidad del Ejército Argentino que conmemora anualmente la ceremonia de su "Bautismo de Fuego" con amplia participación -aunque no plena- de soldados, oficiales y suboficiales propios y “agregados”. Así para el soldado Roberto Velázquez: "Mi palabra siempre va a ser afectiva con este Grupo de Artillería 3. Sigo muy vinculado. Esta es mi casa. No diferencio entre oficiales, suboficiales y soldados. Cada uno tuvo su rol de combate". ${ }^{24}$ Por su parte el soldado Horacio Ghittoni me decía:

En el Centro de Veteranos de [Paso de los] Libres vos ves que los vagos [los soldados veteranos] de otras unidades quieren más a los ingleses que a sus oficiales y suboficiales, porque en la guerra los cagaban de hambre, los maltrataban, los estaquearon. En cambio en el Grupo de Artillería 3 es posible que hagamos una ceremonia como la de hoy [del Bautismo de Fuego] en la que hay oficiales, suboficiales y soldados todos juntos ¡qué diferente fue nuestra experiencia! Los otros soldados odian en lo más profundo de su ser a oficiales y suboficiales que los maltrataron. Esos sentimientos nosotros no los tenemos. Y donde alguno [oficial o suboficial] se zarpaba, a Balza no le temblaba el pulso. ${ }^{25}$

24. Entrevista a Roberto Velázquez realizada por Germán Soprano, Paso de los Libres, 24 de febrero de 2016.

25. Entrevista a José Horacio Ghittoni.
Respecto de estos dos últimos testimonios debe tenerse presente que en la Argentina existen algunas organizaciones de veteranos y eventos conmemorativos de la Guerra de Malvinas en las que los ex-soldados conscriptos y los oficiales y suboficiales no comparten los mismos ámbitos o bien mantienen relaciones conflictivas. Incluso existen casos como los de soldados veteranos de la provincia de $\mathrm{Co}^{-}$ rrientes -entre otros algunos pertenecientes al Regimiento de Infantería 5 de Paso de los Libres- que denunciaron judicialmente a oficiales y suboficiales de sus unidades cometer con ellos graves violaciones a los derechos humanos: "detenciones ilegales", "fusilamientos", "torturas sistemáticas", "vejámenes repetidos" y "desprecio absoluto por la vida" ("estaqueos", "enterramientos", aplicación de "picana eléctrica", sometimiento a "hambre extrema", soldados torturados por su "condición de judíos") que acarreó la muerte de soldados. En el año 2007, el sub-secretario de Derechos Humanos de la provincia de Corrientes, Pablo Andrés Vassel (2007), presentó las primeras denuncias en el Juzgado Federal de Río Grande (Tierra del Fuego) y el CECIM- Centro de Ex Combatientes Islas Malvinas- de La Plata fue parte querellante. ${ }^{26}$ Este tipo de denuncias no fueron referidas por soldados del Grupo de Artillería 3 ni por los "agregados" de otras unidades. Algunos decían -entre ellos Balza- que no pueden negar que eventualmente esas situaciones hayan sucedido en algunas unidades, pero entre ellos no.

Los veteranos del Grupo de Artillería 3 definían como el "Bautismo de Fuego" de su

26.Algunas investigaciones historiográficas tomaron esas denuncias estudiándolas en base a documentación del acervo del fondo "Comisión Especial Malvinas" del Servicio Histórico del Ejército. Abelenda y Villalba (2017) y Ranalletti (2017). 
unidad a las circunstancias experimentadas la noche del 26 al 27 de abril de 1982 en que se abrió fuego de artillería contra una (posible) incursión de fuerzas británicas por el mar. La ceremonia se efectuaba en el cuartel y, por ello, contaba no sólo con la autorización del jefe de la unidad -y de la conducción del Ejércitosino con el apoyo logístico y de infraestructura del mismo. Hacia fines del mes de abril, procedentes de diferentes ciudades y provincias del país, los veteranos del Grupo de Artillería 3 -si bien con predominio de los suboficiales y ex-soldados residentes en Paso de los Libresasistían por un par de días a las ceremonias y conmemoraciones que se realizan en el cuartel. Y aunque como decía más arriba algunos conflictos entre veteranos se prolongaron en el tiempo hasta nuestros días, es preciso destacar que ese poder de convocatoria que alcanzaba a oficiales, suboficiales y soldados, así como a propios y "agregados" de la unidad, se revelaba excepcional en el escenario posguerra donde -por comparación- los veteranos de otras unidades del Ejército no siempre poseían una ceremonia de este tipo donde era dado reunir en un evento al personal de cuadros y los ex-soldados.

Para el soldado veterano Hugo Mango: "Nos juntamos todos en el cuartel. Oficiales, suboficiales y soldados. Eso no pasa en otras unidades donde los cuadros y los soldados están separados, incluso enfrentados. Eso tiene que ver con el jefe". ${ }^{27}$ Esa relativa cohesión interna del Grupo de Artillería 3 puesta en práctica en la Guerra de Malvinas y actualizada en el presente en la ceremonia, no es ajena a la eficacia social que ejerció y continúa ejerciendo el liderazgo militar de Balza sobre sus hombres, especialmente entre suboficiales y soldados

27. Entrevista a Hugo Mango.

62 -muchos de los cuales siguen refiriéndose a él como "mi teniente coronel". Ellos erigen a su jefe en la guerra como una referencia indispensable en el relato de la historia de esta unidad y en el de las historias individuales y grupales de sus veteranos. $Y$ aunque Balza no asistió nunca a la ceremonia su figura ha estado igualmente presente en las alocuciones de autoridades, evocaciones públicas o en las más íntimas de los veteranos, y en las comunicaciones telefónicas o a través de videollamadas, efectuadas por él a modo de salutación en esas ocasiones en que el personal de "su unidad" se reencontraba.

\section{E1 liderazgo de Balza para los veteranos del Grupo de Artillería 3}

Oscar Martínez Conti me había dicho que al regresar de la Guerra de Malvinas "el único que nos entendía era Balza”. ${ }^{28}$ ¿Por qué? ¿Qué significado tenía esa afirmación? ¿Por qué los entendía? ¿Qué entendía? ¿Qué sentido tenía Balza para sus hombres? Intentaré algunas respuestas posibles o plausibles a estas preguntas, no obstante, considerando como presupuesto que los sentidos que aquel teniente coronel Balza del año 1982, el teniente general Balza jefe del Ejército en la década de 1990 y el teniente general retirado desde el año 2000 al presente, tuvo o tiene para cada veterano del Grupo de Artillería 3 es un contenido necesariamente revestido de significados personales e históricamente cambiantes.

Julio César Navone comparaba las diferencias vividas por el Grupo de Artillería 3 y otras

28. Entrevista al general de brigada VGM (R) Oscar Martínez Conti realizada por Germán Soprano, Buenos Aires, 14 de diciembre de 2015. 
unidades del Ejército cuando en los últimos días de la Guerra de Malvinas se replegaron sobre Puerto Argentino ante el avance terrestre de las fuerzas británicas. En esa comparación destacaba el rol cumplido por Balza en la conducción de sus hombres:

En general sin munición, carentes de equipos, de abrigo, agotados por el esfuerzo y las tensiones, sin haber recibido alimentos en las últimas cuarenta y ocho horas, muchos de ellos fuera de la conducción de sus jefes naturales, ya sea por el desordenado repliegue de algunas fracciones o por haber caído éstos muertos, heridos o prisioneros $y$, sin embargo, pese a la gravedad de la situación general, nuestros hombres [los del Grupo de Artillería 3] seguían estoicos al pie del cañón. Junto a nosotros, sereno, agotado por las largas noches de combate pero con gran lucidez para seguir conduciendo la unidad como lo hizo desde el primer día que arribamos a Malvinas, se encontraba nuestro jefe. Agradezco a Dios que en combate fui mandado con firmeza y rigor, pero siempre mediante el ejemplo personal. Eso permitió que ese espíritu llegara hasta el último de los hombres y la unidad haya combatido en forma sobresaliente, pero por sobre todo se haya mantenido monolíticamente la disciplina hasta el último día de combate $\left(\mathrm{Na}^{-}\right.$ vone, 1999, p. 232).

Intentando profundizar en el sentido que Balza tuvo y tiene para los veteranos del Grupo de Artillería 3, en las entrevistas a oficiales, suboficiales y soldados pregunté sobre el final de las mismas si podían definir quién era Balza para ellos. Oscar Martínez Conti me dijo:

Vos me pedís que hable del general Balza y para mi Balza es ese teniente coronel que conocí en Libres en diciembre de 1980 cuando tenía 23 años. Cuando egresé del
Colegio Militar fui destinado a Zapala. Ahí mis primeros mentores fueron un sargento $\mathrm{y}$ un subteniente. Fueron mis primeros modelos de vida como soldado. Después vino Balza. Otros compañeros no tuvieron igual suerte. En Balza yo veo al tipo que me llevó a la guerra y me trajo de vuelta. Yo te puedo hablar de Balza en Malvinas, pero cuando hablo de aquello no pienso en el hombre aislado sino en el Grupo de Artillería 3, en un contexto. Balza era un buen líder, pero el liderazgo no sólo es mérito del que conduce sino de quienes reconocen su liderazgo y lo siguen. Él convencía. Yo veo en Balza al teniente coronel que nos condujo en el combate. Y ahí no estaba solo. Supo transmitir a sus jefes subordinados lo que de ellos pretendía. Ellos dieron sobresaliente respuesta y de allí el éxito del conjunto. ${ }^{29}$

Miguel Ángel Rubio sostuvo que:

Balza fue un verdadero líder en el Ejército. Una cabeza que pensó y ejecutó. Dio el beneficio a los suboficiales de tener estudios secundarios. Como jefe de unidad siempre se preocupó por sus cuadros y los problemas los solucionaba de inmediato. Pero nos tuvo cagando los dos años que estuvo acá (...) [ríe]. ${ }^{30}$

Del mismo modo, Luis María Rodríguez afirmaba:

Cuando llegó a la unidad Balza fue una bisagra para el Grupo de Artillería 3. Tomó como eje central la actividad operacional de la unidad, de toda la unidad, en forma individual y de conjunto. Esa bisagra que

29. Entrevista al general de brigada VGM (R) Oscar Martínez Conti realizada por Germán Soprano, Buenos Aires, 9 de diciembre de 2015.

30. Entrevista al suboficial mayor VGM (R) Miguel Ángel Rubio realizada por Germán Soprano, Paso de los Libres, 22 de febrero de 2016. 
produjo en el Grupo después la traspoló al Ejército cuando fue jefe (...) La unidad es un conjunto de personas que contribuye al fin de ser útil en el teatro de operaciones. Cuando eso no sucede, se perdió lo que es la unidad en su conjunto. A lo mejor los jóvenes no lo percibíamos así entonces. Él nos exigía preparación física e intelectual y nosotros decíamos ¡eh! como si fuera una exigencia desmedida, pero después lo valoramos cuando estuvimos en la guerra, porque ahí aplicamos lo que aprendimos en la instrucción en tiempos de paz. Si nos comparamos con otras unidades, nosotros sí que teníamos espíritu de cuerpo (...) Balza nos bajó un mensaje en la unidad donde cada uno era importante por el trabajo que hace. $^{31}$

A su vez, los soldados Julio Palacio y José Carlos Carbonell decían:

El teniente coronel Balza fue un gran jefe en Malvinas. Le respetábamos mucho. Le teníamos gran admiración como jefe. No permitía errores en el personal. Recorría las trincheras para ver si las habíamos hecho con profundidad porque decía que eso salvaba la vida de los soldados ¡Y guarda si no estaban bien! Era muy difícil hacerlas por las piedras y el suelo con agua. Era muy complicado hacerlas. Él pasaba revista y el soldado tenía que tenerla en condiciones para su protección (...) Si tuviera que volver a servir, serviría en la artillería. Recibíamos los tiros del enemigo, nos refugiábamos y después de protegernos volvíamos a tirar. Eso nos generaba adrenalina. El olor a pólvora. Las condiciones de mando de nuestros oficiales eran excelentes. Estuvimos a la altura de las circunstancias. Entre los artilleros hubo mucha camaradería. ¿Por

31. Entrevista al suboficial mayor VGM (R) Luis María Rodríguez realizada por Germán Soprano, Paso de los Libres, 23 de abril de 2016.

64 qué? Porque estaba impulsada por un jefe: el teniente coronel Balza (...) Le teníamos un gran respeto y, sobre todo, admiración. ${ }^{32}$

Si el Grupo de Artillería 3 tuvo una destacada labor en Malvinas fue por Balza. Nos protegió, fue al frente, siempre estaba a la cabeza como un gran militar. Cuando llegó a jefe del Ejército continuó con el trato con nosotros. No se creyó nada. Para mí él es Martín. Él venía acá [a Paso de los Libres] (... ) Y una vez nos subió a un helicóptero y nos llevó a Yapeyú para una ceremonia de [conmemoración] de San Martín. ${ }^{33}$

Luciano Abel Benítez definió quién era Balza con una idea que éste le transmitió alrededor del año 1966 cuando él era un joven cabo: "Usted no tiene que confundir disciplina con obsecuencia. Tiene que ser subordinado. Hacer lo que se le ordena. Pero siempre que la orden esté bien hecha. Y entonces usted tiene que decidir cuándo lo hace y cuándo no". ${ }^{34}$ Por su parte, para Guillermo Castillo:

La base del buen desempeño de la unidad en Malvinas fue la preparación y la instrucción durante la paz. Balza era un jefe duro, un hijo de puta [sonríe] tanto en la paz como en la guerra. Pero usted nunca va a encontrar un soldado que diga que el teniente coronel [Balza] no compartía lo mismo que ellos. Después de cada fuego de contrabatería la presencia del jefe [Balza] se hacía notar. Se ocupaba del personal. Se subía al jeep con Quiroz e incluso iba a

32. Entrevista a Julio Palacio realizada por Germán Soprano, Paso de los Libres, 23 de febrero de 2016.

33. Entrevista a José Carlos Carbonell realizada por Germán Soprano, Paso de los Libres, 24 de febrero de 2016.

34. Entrevista al suboficial principal VGM (R) Luciano Abel Benítez realizada por Germán Soprano, Paso de los Libres, 24 de febrero de 2016. 
ver a la Batería $\mathrm{C}$ que estaba más alejada. Eso sí, si venía y encontraba algún detalle mal hecho, te cagaba a pedos. En eso era tan jodido en la paz como en la guerra. Uno sabía que con el jefe no se jodía. Y si mi jefe está acá -pensábamos- yo no tengo más que seguirlo. No sabés cómo eso eleva la moral (...) Fuimos como unidad y volvimos como unidad. Y tuvimos solo dos muertos. En esto también se puede constatar que la instrucción era excelente. Hoy el espíritu de la unidad está intacto. Esta no es, por eso, una unidad cualquiera. ${ }^{35}$

El universo de sentidos que despertaba Balza entre los veteranos, no obstante, no se agota en estas apreciaciones positivas. Otros testimonios -si bien minoritarios- reunidos en entrevistas o en conversaciones informales dan cuenta cómo en perspectiva de algunos veteranos su valoración como jefe militar y persona podía ser objeto de críticas, fundamentalmente, centradas en su rol como jefe de Estado Mayor General del Ejército antes que por su desempeño en la Guerra de Malvinas como jefe del Grupo de Artillería 3. Esas críticas eran más acentuadas en algunos cuadros, especialmente, oficiales. Durante su entrevista un suboficial del cuerpo profesional manifestó apreciaciones a veces críticas, otras abiertamente laudatorias, sobre el liderazgo y la personalidad de Balza como jefe militar en tiempos de paz y de guerra. Después de relatar cómo Balza siendo jefe del Grupo de Artillería 3 había ponderado su labor en el cuartel reparando y poniendo a punto los vehículos de la unidad, dijo:

Fue un gran jefe, siempre atento, siempre dispuesto. Mandó con el ejemplo (...) Le tengo mucho aprecio como líder. En tiem-

35.Entrevista al sargento primero VGM (R) Guillermo Castillo realizada por Germán Soprano, Paso de los Libres, 22 de abril de 2016. pos de paz también mandaba la unidad con el temor. Era perfeccionista. Implacable. Castigaba mucho. A gente grande con hijos los tenía encerrados acá [en el cuartel]. Pero allá, en el combate, mostró su mejor faceta de soldado (...) Después que volvió de Malvinas se dedicó a hacer política. ${ }^{36}$

Esta última afirmación sobre dedicarse a hacer política era una crítica a su desempeño como jefe del Estado Mayor General del Ejército. Otros cuadros lo cuestionaban por lo dicho y hecho desde este último cargo. En una breve saludos de presentación ante un oficial retirado veterano "agregado" al Grupo de Artillería 3 durante la guerra. Tras un apretón de manos dije que era investigador del CONICET y profesor de las Universidad Nacionales de Quilmes y La Plata y estaba realizando una "investigación sobre el general Balza". Mi interlocutor acotó con irónica malicia: "una investigación ¿para el FBI?”. Poco después me explicaría el porqué de aquellas palabras:

Habrá notado por lo que le dije de su investigación que yo no aprecio a Balza. Para mí es despreciable, mentiroso, oportunista. Nunca nos llevamos bien. Lo conozco desde que él era instructor en el Colegio Militar y yo cadete. Cuando en abril del ' 82 me enviaron al Grupo de Artillería 3 yo dije: justo me van a enviar a esta unidad y que encima no sé si va a ir a Malvinas. Balza me recibió diciéndome: ¿qué hace usted acá? Después de la guerra tuvimos un tiempo en que las cosas estuvieron más o menos bien. Él me reconoció como soldado y supongo que eso a él le sirvió. Luego tuvo ese discurso de la autocrítica y escribió esos cuatro libros despreciables donde miente e insulta a quienes fueron sus jefes, criticándolos cuan-

36. Entrevista al suboficial principal VGM (R) Jorge Quiroz realizada por Germán Soprano, Paso de los Libres, 22 de febrero de 2016. 
do le convino y después de no haber dicho nada cuando debía haber hablado. También están las causas armas y Río Tercero donde no está condenado y preso porque vaya a saber qué pacto hizo. Porque nunca le podrían haber faltado las piezas [de artillería] al Ejército sin su consentimiento. Yo hablé con el fiscal [Carlos] Stornelli y le dije que tenía que hacer para seguir el camino de las armas hasta Balza, pero él lo quería a [Carlos] Menem. Por eso le digo que si quiere hablar conmigo va a tener una mirada crítica. ${ }^{37}$

En una conversación informal que mantuve con otro oficial veterano "agregado", también se explicitaron críticas, si bien -por contraste con la anterior- éstas se evidenciaban en la parquedad de los comentarios y en la ausencia de un reconocimiento positivo explícito a su conducción en la guerra. Cuando le pregunté por la relación con Balza me respondió:

Cuando llegué al Grupo de Artillería 3 ya sabía que Balza era un jodido (...) Fue el jefe que tuve en la guerra. El único jefe que tuve en la guerra. En la única guerra en la que estuve. No puedo decir mucho más. A mi posición vino lo suficiente. Ni mucho ni poco. Quizá hubiera sido mejor un poco menos, pero somos así, si el jefe viene mucho no es bueno y también nos quejamos si viene poco. De cómo fue Balza en la guerra no puedo decir mucho. Quizá faltó un poco de comida en mi posición, no para mí, sino para los soldados. Yo sólo conozco lo que pasó en mi batería. De lo que hizo después de Malvinas cuando era jefe del Ejército, lo

37. Conversación informal con un oficial veterano retirado "agregado" al Grupo de Artillería 3 en la guerra de Malvinas y Germán Soprano, Paso de los Libres, abril de 2016. que dijo o no dijo, lo que hizo o dejó de hacer, de eso no voy a hablar. ${ }^{38}$

Pero tras completar aquel comentario crítico, este oficial contó una historia en la que se ponderaba el cuidado que Balza dispensó a sus hombres en la posguerra. Se trataba de la historia de un suboficial veterano del Grupo de Artillería 3 cuyo hijo padecía una grave discapacidad y que recurrió a su antiguo jefe de unidad buscando ayuda para acceder a una costosa silla ortopédica importada de Estados Unidos que -esperaba- contribuiría a mejorar la calidad de vida del chico y las posibilidades de sus padres de atenderlo. Aquel suboficial telefoneó a Balza cuando este era embajador argentino en Colombia y le explicó cuál era su problema y que la asistencia médica y social del Ejército no le solucionaba o sólo lo hacía parcialmente con un aporte económico que no permitía solventar los gastos para adquirir aquella silla:

Balza le dijo que él no se lo podía resolver, pero que iba a hablar con un general que era de su más estrecha confianza y que en breve tendría noticias. Al día siguiente -sorprendido- el suboficial recibió un llamado de ese general diciéndole que estaba todo arreglado y que debía esperar unos días más. Dos semanas después el hijo del suboficial tenía su silla. Y sí, eso es Balza también. ${ }^{39}$

Contrariamente, soldados y muchos suboficiales veteranos del Grupo de Artillería 3 tendían abiertamente a ponderar la personalidad y el desempeño de Balza tanto en la guerra como cuando fue jefe del Ejército y aún en la actua-

38. Conversación informal con un oficial veterano retirado "agregado" al Grupo de Artillería 3 en la guerra de Malvinas.

39. Conversación informal con un oficial veterano retirado "agregado" al Grupo de Artillería 3 en la guerra de Malvinas. 
lidad. Surgía con cierta recurrencia la invocación a anécdotas de encuentros entre aquellos y Balza durante la posguerra. Unos encuentros que guardaban entre sí un rasgo en común: se producían cuando alguno de sus hombres le solicitaba ayuda para sobrellevar una difícil situación de salud o laboral propia o de un familiar, por algún problema relacionado los destinos militares en sus carreras profesionales o con el reconocimiento como veterano, o en bien simplemente cuando lo buscaban en Buenos Aires al solo efecto de saludarlo y éste rompía compromisos institucionales o de agenda previos para recibirlos. Miguel Ángel Rubio decía que:

Después de la guerra quedó una amistad con Balza, Martínez Conti, Milanese (...) Yo siempre le dije jefe, otros mi teniente coronel, otros Martín (...) Cuando Balza era subdirector del Colegio Militar mi señora tenía que ser trasladada al Hospital Militar en Buenos Aires. Llegamos allá y no la atendieron con urgencia. No sabía qué hacer. Lo llame por teléfono Balza al Colegio y me atendió. No se preocupe, me dijo. Balza llamó al Hospital y me asignaron una pieza para mi señora. Estuvo tres días internada. Como no me dejaban quedarme acompañándola por la noche, le dije al médico: mire, no puedo dejar sola a mi señora acá, si no me da una respuesta favorable voy a tener que llamar a Balza. No, está bien, me dijo resignado, quédese nomás [ríe]. ${ }^{40}$

Hugo Mango no consideraba que lo unía a Balza un lazo de amistad. Para él: "Balza es un tipo muy recto, derecho. Podía cometer injusticias como cualquiera. Para nosotros en el servicio militar y en la guerra fue un buen jefe. $\mathrm{Y}$ lo digo no porque seamos amigos, porque

40. Entrevista al suboficial mayor VGM (R) Miguel Ángel Rubio. yo no soy su amigo". ${ }^{41}$ Por su parte José María González Fernández decía:

Balza es una buena persona. Tuve mucho contacto con él. Me decían "el hijo de Balza”. Como suboficial mayor ascendí primero en el arma [de artillería]. Cuando era Jefe del Ejército, le avisaba que quería verlo y él me hacía pasar a su oficina o donde estuviera sin importar qué estaba haciendo o con quién estaba. Yo conocí a su esposa, la finada María Inés, y a su cuñado el general [Antonio] Serrano (...) No tengo palabras. Es espectacular. Porque, como dice el refrán, cuando le toqué la puerta, él respondió. ${ }^{42}$

Jorge Quiroz cuenta que durante la posguerra su esposa tuvo que ser internada en una clínica y él la acompañó muy preocupado por su estado de salud. En esas circunstancias:

un subteniente que me tenía bronca me ordenó presentarme en el cuartel. Yo le dije que no podía, le expliqué por qué, pero me mandó buscar con dos suboficiales alcahuetes. También les dije que no ¡qué hago entonces! Lo llamo a Balza que estaba de comandante de Brigada en Neuquén. Hablé personalmente con él y me dijo que ya se ocupaba. Llamó al comandante de mi Brigada y les ordenaron al jefe de mi unidad $\mathrm{y}$ al subteniente que no me jodieran. Los levantaron en peso. ${ }^{43}$

41. Entrevista a Hugo Mango.

42. Entrevista al suboficial mayor VGM (R) José María González Fernández.

43. Entrevista al suboficial principal VGM (R) Jorge Quiroz. 
De igual modo, Guillermo Castillo recuerda que a fines de 1983 le salió el pase del Grupo de Artillería 3 a la Escuela de Artillería en Campo de Mayo donde estuvo durante el año 1984. En su percepción ese destino "era un desastre” y, por ello, tomó una decisión para tratar de resolver esa situación que lo afectaba negativamente:

Le llamo a Balza y le pido que me saque de la Escuela. Él estaba en el Colegio Militar. Me dice que lo llame en el mes de julio. Lo llamé y hablé también con Martínez Conti que estaba con él. Le dije que quería volver al Grupo de Artillería 3, si era posible. Y si, en 1985 volví a Libres. ${ }^{44}$

En la posguerra Balza podía intervenir ayudando a un soldado veterano a obtener un empleo en el medio civil si este se lo solicitaba y si ello estaba al alcance de sus posibilidades y relaciones. Tal fue lo que sucedió con el soldado Marcos Falcón:

Cuando volví de Malvinas no quería hablar de la guerra con nadie. Conseguí un trabajo en mi pueblo y me quedé tres meses. Después me fui a Buenos Aires (...) Una vez un veterano de otra unidad me dice ¿Por qué no lo vamos a ver a Balza? (...) Lo llamo y me da una cita. Almorzamos. Me preguntó otra vez por el trabajo y cuando le conté nos ofreció a los dos. Ahí mismo llamó por teléfono al intendente [Saúl] Bouer y a los quince días entré a trabajar a la municipalidad de Buenos Aires con categoría D4. Desde entonces nunca más perdí el contacto con él. ${ }^{45}$

44. Entrevista al sargento primero VGM (R) Guillermo Castillo.

45. Entrevista a Marcos Falcón realizada por Germán Soprano, Buenos Aires, 12 de mayo de 2016.

68
Horacio Ghittoni no perdió la relación personal con Balza. Fue presidente del Centro de Veteranos de Guerra en Paso de los Libres entre 1989-1990 y 2002 y desarrolló una carrera política como dirigente del Partido Justicialista llegando a ser presidente del Concejo Deliberante de esa ciudad:

Martín apoyó a nuestro Centro de Veteranos, nos dio una camioneta Ford que tenemos todavía, uniformes, bandera de ceremonia. Él con [Paso de los] Libres tiene una muy buena relación. El 2 de abril de 1999 yo era presidente del Concejo Deliberante, hicimos un acto importante, y lo trajimos. Balza es un militar distinto, muy profesional, una buena persona. Conmigo siempre fue muy generoso. Sé que no es muy querido en la Fuerza. Se me hace que por la autocrítica no lo quieren en el Ejército. En la despedida que le hicieron en [el Regimiento de] Patricios en 1999 mucha gente no le daba pelota. Escuché, creo, que alguno dijo: al fin se va este hijo de puta. Y él estuvo con nosotros -con Navone, Castillo y conmigo- tomando el vino de honor en esa ceremonia. ${ }^{46}$

Hugo Mango me contó que en 1992 o 1993 viajó con su esposa desde Paso de los Libres a Buenos Aires a visitar familiares y aprovechando la ocasión decidió comunicarse con Balza -por entonces jefe del Estado Mayor General del Ejército- para coordinar un encuentro apenas para saludarlo. Lo citó a las 7:30 horas de la mañana en el Edificio Libertador. Hugo fue al encuentro con su esposa, pero previendo que sería breve, ella permaneció en el acceso al

46. Entrevista a José Horacio Ghittoni. Con la "autocrítica" Ghittoni se refería a un mensaje institucional de Balza como jefe del Ejército el 25 de abril de 1995 manifestando una autocrítica por los crímenes de lesa humanidad cometidos por esa Fuerza durante la última dictadura. 
edificio y él subió hasta el piso donde estaba la jefatura del Ejército. Al llegar al despacho le informaron que Balza había tenido un cambio de agenda y que iría directamente desde su domicilio hasta el Museo de la Artillería en Ciudadela a una reunión con generales. Lo llevarían en un vehículo hasta aquella localidad del conurbano bonaerense y partieron rápidamente con Hugo todavía sopesando cuánto tiempo demoraría en regresar, pues no había avisado a su esposa de ese imprevisto cambio de planes (recordemos que eran tiempos previos a la difusión del celular). Al llegar a destino su antiguo jefe lo saludó emotivamente y se alegró del reencuentro, pero "no pudo darle mucha bola" y lo invitó a quedarse a almorzar. Así todo, Hugo no compartió la mesa con los generales. Finalizado el almuerzo, Balza le solicitó que se acerque a la mesa; con expresión firme y el rostro sonriente dijo ante aquella audiencia de oficiales superiores que conducían al Ejército: "Hugo, a ver, cuéntele a los generales cómo es el tiro de artillería en combate". ${ }^{47}$ No sería esta la primera ni la única vez, pues, que Balza exhibía satisfecho y orgulloso la experiencia como combatientes de sus "bravos soldados litoraleños" del Grupo de Artillería 3 ante militares profesionales, más aún si se trataba de inexpertos oficiales superiores que no habían vivido la guerra en carne propia.

\section{Conclusiones}

El presente artículo es un aporte al conocimiento de las relaciones de solidaridad y conflicto entre individuos y grupos del Grupo de Artillería 3 del Ejército Argentino que combatieron en la Guerra de Malvinas, comprendien-

47.Entrevista a Hugo Mango. do esas relaciones-en sus propias perspectivas y experiencias- antes, durante y en la posguerra. Busqué demostrar que si bien la producción de las relaciones de mando y obediencia, jerarquía y disciplina definen atributos sociales constitutivos de la organización y funcionamiento de una unidad militar, dichos atributos deben ser analizados en su historicidad, pues se gestaron en torno del adiestramiento y la instrucción del personal del Grupo de Artillería 3 antes de la guerra y fueron puestos a prueba -no sin conflictos- en el contexto extremo del combate en la guerra. Señalé también que la solidaridad y camaradería entre oficiales, suboficiales y soldados y el ascendiente personal de sus líderes -especial, pero no exclusivamente, el del jefe de la unidad, Martín Antonio Balza- fueron atributos destacados por los combatientes como determinantes en sus experiencias de guerra. Y sostuve, además, que esas relaciones de solidaridad y conflicto al interior y entre estamentos castrenses y en los vínculos interpersonales antes y durante la guerra fueron resignificadas y actualizadas por sus protagonistas -reconociendo continuidades y cambios- en distintas circunstancias y escenarios de la posguerra.

Asimismo, considero que la contribución del artículo no es sólo sustantiva sino también metodológica, pues entiendo que una historia social y cultural o antropología de la guerra que estudie a los combatientes argentinos en esa guerra tiene por desafío profundizar en dos cuestiones-entre otras- poco exploradas por las ciencias sociales en la Argentina: reconocer las perspectivas y experiencias de combate de los veteranos desde sus inscripciones y participación en la guerra en unidades militares específicas; y comprender la historicidad de esas relaciones de solidaridad y conflicto entre los veteranos de una unidad militar en su devenir antes, durante y en la posguerra. Brevemente, 
sistematizo mis argumentos en favor de estos dos desafíos.

Por un lado, es necesario delimitar y profundizar en el estudio histórico de unidades militares específicas -o de elementos de ellas- a efectos de considerar la incidencia en el combate de su alistamiento y de la instrucción y adiestramiento de su personal, el conocimiento de los perfiles y trayectorias colectivas e individuales de sus oficiales, suboficiales y soldados antes de la guerra, en particular, el análisis de los procesos de adquisición de sus saberes y prácticas socio-profesionales, identidades, formas de sociabilidad y de organización en cada Fuerza Armada, arma, especialidad, aptitud especial y jerarquía en la cadena de mando castrense. Dicho abordaje es reconocible en investigaciones sobre pilotos de A4B de la Fuerza Aérea Argentina y marinos del ARA General Belgrano (Rosana Guber), el Regimiento de Infantería 5, Regimiento de Infantería Mecanizado 8 y Compañía de Ingenieros 9 destinados en la isla Gran Malvina (Federico Lorenz), el Apostadero Naval Malvinas (Andrea Belén Rodríguez), buzos tácticos (Pablo Melara), el Batallón de Infantería de Marina 5 (Alejandro Corbacho), el personal femenino de sanidad militar (María Pozzio) y la artillería de campaña del Ejército Argentino (Germán Soprano). ${ }^{48} \mathrm{El}$ desarrollo de estas y nuevas investigaciones en ciencias sociales debe dialogar críticamente con la literatura institucional de las Fuerzas Armadas, testimonial de los veteranos y periodística sobre la Guerra de Malvinas, pues éstas han otorgado y otorgan un lugar relativamente más destacado en sus relatos e historias de guerra a las unidades militares y sus integrantes.

48.Trabajos de referencia de estos investigadores han sido citados más arriba.
Por otro lado, es preciso profundizar en el estudio de las formas de solidaridad y conflicto entre los combatientes en sus inscripciones en $\mathrm{y}$ relaciones con diferentes marcos temporales y escenarios espaciales, pues esas formas de solidaridad y el conflicto al interior de una unidad militar -o los elementos de aquella- tienen su propia historia y, por tanto, su análisis requiere del conocimiento de las historias de los individuos, grupos y sus relaciones antes, durante y en la posguerra. En este sentido, el recurso metodológico indispensable a los testimonios orales -a través de entrevistas y/o el registro del trabajo de campo etnográfico- debe emplearse reconociendo el carácter situado de la producción de los mismos, esto es, efectuados en diferentes circunstancias históricas en la posguerra de Malvinas. De allí que sea necesario reconstruir cómo fue la historia de esas formas de solidaridad y conflicto sirviéndose de otras fuentes documentales -informes oficiales, Libro Histórico y Diario de Guerra de las unidades, Legajo del Personal Militar $\mathrm{u}$ otros- $\mathrm{y} / \mathrm{o}$ problematizando la producción e interpretación de aquellos testimonios orales. Esto último supone un desafío adicional, pues en la producción de conocimientos sobre historia reciente existe cierto solapamiento entre historia y memoria que, en ocasiones, favorece una interpretación extemporánea de los fenómenos del pasado y de los testimonios de sus protagonistas. $^{49}$

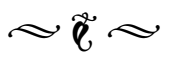

49. Sin dudas, es posible diferenciar analíticamente las nociones de historia y memoria, pero reconociendo que entre ambas se producen interrelaciones o interpelaciones mutuas, descartando por ello interpretaciones que las consideran como términos antitéticos (Franco y Levín, 2007). 


\section{Referencias Bibliográfica}

Abelenda, F. y Villalba, V. (2017). Guerra de Malvinas. Un análisis de documentos del archivo del Ejército. Aletheia, 8(15), 1-20.

Alexiévich, S. (2016). Los muchachos de zinc. Buenos Aires: Debate.

Balza, M. (2003). Malvinas. Gesta e incompetencia. Buenos Aires: Atlántida.

Caballero, L. A. (1999). No íbamos a un paseo. En M. Balza (Coord.), Así peleamos. Malvinas. Testimonios de veteranos del Ejército (pp.112-118). Buenos Aires: Fundación Soldados.

Chao, D. (2017). Ser excombatiente en los 80. Identidad y condiciones en la génesis del CESCEM Corrientes. La trama de la comunicación, 21(2), 51-70.

Corbacho, A. (2003). Factores organizacionales y desempeño en combate: la experiencia de la IMARA en Malvinas. Serie Documentos de Trabajo, 255, 1-24.

Franco, M. y Levín, F. (2007). El pasado cercano en clave historiográfica. En M. Franco y F. Levín (Comps.), Historia reciente. Perspectivas y desafíos para un campo en construcción (pp. 31-66). Buenos Aires: Paidós.

Grupo de Artillería 10 (2012). Así combatimos. La historia de los cañones de Junín en la Guerra de Malvinas. Junín: Fundación Soldados / Ediciones de las Tres Lagunas.

Guber, R. (2004). De chicos a veteranos. Memorias argentinas de la guerra de Malvinas. Buenos Aires: Antropofagia.

Guber, R. (2008). Crucero ARA General Belgrano in memóriam. Linajes político-navales en las memorias de Malvinas. Revista de Ciencias Sociales Iberoamericana, 30, 7-26.

Guber, R. (2013). Como un cierre. Igualdad, honor y amistad entre contendientes directos durante la postguerra de Malvinas. Tabula Rasa, 19, 11-27.

Guber, R. (2016). Experiencia de halcón. Buenos Aires: Sudamericana.

Lorenz, F. (2006). Las guerras por Malvinas. Buenos Aires: Edhasa.

Lorenz, F. (2009). Malvinas. Una guerra argentina. Buenos Aires: Sudamericana.

Lorenz, F. (2014). Gran Malvina. Una mirada a la experiencia bélica desde los testimonios de sus oficiales. Anuario Colombiano de Historia Social y de la Cultura, 4(2), 225-257.

Melara, P. (2010). 80 dias en Malvinas. El accionar de la Agrupación de Buzos Tácticos durante el conflicto bélico del Atlántico Sur (Tesis de Licenciatura inédita). Universidad Nacional de Mar del Plata, Mar del Plata, Argentina. 
Navone, J. C. (1999). Disparando el "gran Berta”. En M. Balza (Coord.), Asi peleamos. Malvinas. Testimonios de veteranos del Ejército (pp.139-143). Buenos Aires: Fundación Soldados.

Panizo, L. (2016). La guerra sentida: símbolos rituales entre familiares y excombatientes de la Guerra de Malvinas. Sociedad y Religión, 46(26), 84-113.

Pozzio, M. (2015). La experiencia de las mujeres en Malvinas: de la Sanidad Militar al reconocimiento. Cuadernos de Marte. Revista Latinoamericana de Sociologia de la Guerra, 6(8), 129-157.

Ranalletti, M. (2017). Y en las islas también. Rupturas y continuidades entre la campaña de represión clandestina (1974-1983) y la Guerra de Malvinas (1982). Pasado Abierto, 5, 23-40.

Rodríguez, A. B. (2009). Cotidianeidad y guerra. Experiencias de los integrantes del Apostadero Naval Malvinas en el conflicto del Atlántico Sur. Antitese, 2(4), 937-968.

Rodríguez, A. B. (2015). La memoria social de los ex-soldados combatientes en el Apostadero Naval Malvinas en el Conflicto del Atlántico Sur. Un análisis a través de las anécdotas recurrentes del grupo. Revista Universitaria de Historia Militar, 4(8), 164-182.

Soprano, G (2018a). La formación profesional de los oficiales artilleros del Ejército Argentino entre la Segunda Posguerra Mundial y la Guerra de Malvinas. En A. Fuccille, L. Goldoni y M. Oliveira Aldao. (Eds.), Forças Armadas e Sociedade Civil: Atores e Agendas da Defesa Nacional no Século XXI (pp. 51-88). São Cristóvão: Associação Brasileira de Estudos de Defesa.

Soprano, G. (2018b). El Ejército Argentino y la guerra convencional en la segunda mitad del siglo XX. Reflexiones a partir de la experiencia de la artillería en la Guerra de Malvinas. Contenciosa. Revista sobre violencia politica, represiones y resistencias en la historia iberoamericana, 8, https://doi.org/10.14409/ contenciosa.v0i8.8595

Vassel, P. (Comp.) (2007). Memoria, verdad, justicia y soberanía. Corrientes en Malvinas. Corrientes: Subsecretaría de Derechos Humanos. 